\title{
La protección jurisdiccional frente al ruido (comentario a la Sentencia del Tribunal Constitucional 119/2001, de 24 de mayo)
}

\author{
José Pérez Martos \\ Profesor de Derecho Administrativo \\ Universidad de Granada
}

Sumario: I. PRELIMINAR. II. ANTECEDENTES. III. LA POSICIÓN DEL MINISTERIO FISCAL. IV. FUNDAMENTOS DE DERECHO. V. FALLO. VI. VOTOS PARTICULARES. VII. CONSIDERACIONES FINALES.

\section{PRELIMINAR}

El Tribunal Constitucional (en adelante, TC), en la Sentencia 119/2001, de 24 de mayo ${ }^{1}$, desestima el recurso de amparo interpuesto por una vecina del municipio de Valencia contra la Sentencia de 21 de junio de 1998 de la Sala de lo Contencioso-Administrativo, Sección Primera, del Tribunal Superior de Justicia de la Comunidad Valenciana (en adelante, TSJCV) que, a su vez, desestima la reclamación formulada al Ayuntamiento del citado municipio en concepto de indemnización por daños y perjuicios experimentados, como consecuencia de los ruidos producidos, fundamentalmente, por establecimientos públicos existentes en la zona donde se hallaba su domicilio.

Esta Sentencia ${ }^{2}$ del TC establece una importante doctrina sobre la incidencia del agente contaminante del ruido en los derechos fundamentales y, con ello, una aportación no menos relevante a nuestro sistema de Derecho ambiental. A este extremo, es decir, a la dimensión ambiental de la Sentencia circunscribiremos, principalmente, el presente trabajo. Acotación ésta que realizamos en este apartado Preliminar para dejar constancia del tratamiento más leve con que abordaremos otras cuestiones que la citada Resolución suscita.

\footnotetext{
${ }^{1}$ BOE n. ${ }^{\circ} 137$ (Suplemento), de 8 de junio.

2 Sobre esta S. vid. M. GÁmez Mejías, «La relevancia constitucional de la contaminación acústica: el contenido ambiental de los derechos fundamentales», RIGA núms. 32/33, 2001, pp. 59 y ss., y M. Pulido Quecedo, «Sobre la defensa frente al ruido y el derecho a la "intimidad domiciliaria"», RATC (Tribuna), n. ${ }^{\circ} 8,2001$, pp. 9 y ss.
} 


\section{ANTECEDENTES}

1. La recurrente, vecina del municipio de Valencia, solicitó al Ayuntamiento de dicha ciudad el abono de una cantidad en concepto de indemnización por daños y perjuicios, al considerar que la citada Administración ha vulnerado sus derechos fundamentales a la vida, a la salud y a la inviolabilidad del domicilio. Fundamenta la actora su pretensión en el funcionamiento anormal del Ayuntamiento «al no haber actuado diligentemente en defensa de los derechos e intereses legítimos de los vecinos del lugar, haciendo uso para tal fin de las potestades que le confiere el ordenamiento jurídico». Pues ha tenido que soportar en su domicilio, situado en «Zona Acústicamente Saturada», ruidos procedentes tanto de los establecimientos ubicados en dicha zona como de una discoteca situada en los bajos de la finca donde reside. Las referenciadas molestias le provocaron insomnio y la obligaron a la realización de obras en su domicilio.

2. El Ayuntamiento no resuelve sobre la solicitud cursada. Ante la ausencia de dicha resolución expresa, la recurrente interpone recurso contencioso-administrativo por la vía de protección de los derechos fundamentales ${ }^{3}$ ante el TSJCV. Dicho recurso es admitido a trámite, declarándose por la Sala no haber lugar a la solicitud de inadmisibilidad formulada por la representación letrada de la Administración demandada.

3. Admitido a trámite el recurso, la recurrente formula demanda suplicando al Tribunal lo solicitado ante el Ayuntamiento. Súplica que fundamenta en la pasividad e inactividad de la Corporación ante la emisión de ruidos por encima de lo legislado ${ }^{4}$, en el incumplimiento de los horarios de cierre por los establecimientos y locales existentes en la zona, y en la ausencia de respuesta del Ayuntamiento ante las denuncias formuladas. Alega la parte actora que la Administración demandada, con dicha pasividad e inactividad, le ha provocado la degradación de su medio ambiente, continuas injerencias en la privacidad de su domicilio, insomnio, y la necesidad de realizar obras en su domicilio con la finalidad de evitar los efectos del ruido producido ${ }^{5}$. Y, con ello, una vulneración de los artículos 15 y 18.1 y 2 de la CE.

\footnotetext{
${ }^{3}$ Ley 62/1978, de 26 de diciembre, de Protección Jurisdiccional de los Derechos Fundamentales de la Persona.

${ }^{4}$ El ruido en la calle sobrepasaría los $65 \mathrm{~dB}(\mathrm{~A})$ en horario nocturno los fines de semana [Antecedente 2.d)].

${ }^{5}$ La actora reclamaba la cantidad total de 649.280 ptas., de las que 500.000 ptas. lo eran en concepto de daños y perjuicios por razón de los trastornos del sueño sufridos, y las 149.280 ptas. restantes se correspondían con la cantidad a que ascendieron las obras que se vio obligada a realizar para evitar los efectos del ruido.
} 
Por su parte, la representación letrada del Ayuntamiento se opone a la demanda alegando motivos procesales ${ }^{6} \mathrm{y}$ de fondo, consistentes, estos últimos, fundamentalmente, en que no han resultado probados ni el daño alegado ni que el nivel de ruidos experimentado por la recurrente en su domicilio superara los límites fijados en la Ordenanza municipal de aplicación.

4. El Tribunal acuerda el recibimiento del proceso a prueba donde cada una de las partes aportan las relacionadas en el Antecedente 2, letra g) de la Sentencia. Interesando destacar en este comentario que la parte recurrente presenta unas mediciones de ruidos realizadas fuera de su domicilio, un documento médico consistente en un parte de consulta y hospitalización expedido por facultativo donde consta que durante varios años estuvo en tratamiento por insomnio, y una factura de una empresa de carpintería donde se acredita la cuantía a que ascendieron las obras llevadas a cabo en un balcón y una ventana de su domicilio. Por su parte, la demandada, entre otras, aporta una certificación del Secretario del Ayuntamiento donde consta la tramitación de un total de 37 expedientes sancionadores contra la discoteca situada en los bajos del domicilio de la recurrente por infracción a la Ley autónomica de Espectáculos, Establecimientos Públicos y Actividades Recreativas ${ }^{7}$.

5. Concluida la fase de prueba, la Sala de lo Contencioso-Administrativo del TSJCV dicta Sentencia desestimatoria de la pretensión de la actora imponiéndole las costas procesales. El Tribunal, en la resolución del fondo del asunto, se limita a enjuiciar sólo si el acto administrativo impugnado, es decir, la desestimación por silencio administrativo de la reclamación formulada, vulnera los artículos 15 y 18.1 y 2 de la CE. Y, en este sentido, considera que, a la vista de las pruebas practicadas, no se aprecia infracción de los preceptos citados. Pues, de una parte, según el informe aportado por el Ayuntamiento sobre mediciones realizadas en el zaguán colindante a la discoteca, la intensidad del ruido oscila entre los 35 y $37 \mathrm{~dB}(\mathrm{~A})$ y «a tal intensidad no puede atribuírsele los efectos pretendidos de considerarse vulnerados los artículos 15 y 18.1 y 2 de la $C E » 8$; $\mathrm{y}$, de otra parte, el informe médico aportado por la actora, en el que fundamenta los efectos del ruido padecido sobre su salud, «se limita a indicar

\footnotetext{
${ }^{6}$ En este sentido se alega: carácter prematuro del recurso (interposición antes de que acabara el plazo para resolver), inadecuación de procedimiento, e incompetencia de jurisdicción, toda vez que el daño padecido por la actora no es debido al funcionamiento anormal de la Administración sino que, antes bien, ha de ser insertado en el ámbito de las relaciones de vecindad.

${ }^{7}$ Ley $2 / 1991$, de 18 de febrero.

${ }^{8}$ Fundamento de Derecho Segundo.
} 
que la actora ha estado varios años en tratamiento por insomnio, pero sin especificar en qué tiempo y por qué causa, añadiendo que actualmente no necesita tratamiento, ante lo cual, en base al resultado de la prueba practicada, no cabe apreciar en el presente caso una vulneración de los derechos fundamentales reseñados» ${ }^{9}$. En virtud de lo anterior, la Sala de lo Contencioso-Administrativo del TSJCV desestima el recurso interpuesto por la demandante, y ello sin perjuicio de que pueda hacer valer dicha reclamación mediante el proceso ordinario. Ciertamente, la desestimación del citado recurso se produce por no haber quedado probados los extremos en los que la recurrente fundamenta su pretensión. Es decir, por falta de pruebas.

6. Disconforme la actora con lo resuelto por el TSJCV formula recurso de amparo ante el TC, alegando, en este sentido, que la Sentencia dictada por el citado Tribunal Superior de Justicia vulnera los artículos 14 y 24 de la CE y deja sin protección los derechos fundamentales proclamados en los artículos 15 y 18 de la CE, cuyo reconocimiento se pretendía en el proceso judicial que dio origen a la citada Sentencia. En relación con la vulneración del artículo 24 se alega no apreciación conjunta de la prueba y falta de motivación suficiente en la Sentencia, sobre todo, respecto de la intensidad del ruido que la Sala considera probado. Respecto de la vulneración del artículo 14 se manifiesta que el TSJCV con la Resolución recurrida quebranta la igualdad en la aplicación de la Ley, y ello con fundamento en que en Sentencia de 7 de marzo de $1997^{10}$, la Sala de lo Contencioso-Administrativo, Sección Tercera, adoptó un criterio distinto concurriendo identidad de supuestos y de razones de pedir. Y, en último lugar, se alega que la Sentencia impugnada no ha reparado los derechos fundamentales afectados por la actitud pasiva del Ayuntamiento al no haber adoptado las medidas adecuadas en defensa de los derechos e intereses legítimos de los vecinos afectados por las molestias producidas por las actividades existentes en la zona, considerada, en la propia Ordenanza municipal, como acústicamente saturada.

\footnotetext{
9 Supra.

${ }^{10}$ En esta S. el Tribunal considera que los ruidos existentes en una zona, producidos por distintos establecimientos públicos, y que superan los niveles permitidos por la Ordenanza municipal de aplicación, vulneran los derechos fundamentales del recurrente consagrados en los artículos $15 \mathrm{y}$ 18.1 y 2; condenando al Ayuntamiento a que abone a aquél una cantidad (importe de gastos por insonorización de su vivienda más una cantidad en concepto de gastos morales por las molestias experimentadas), al considerar a esta Administración «responsable por su comportamiento activo permitiendo la apertura de los establecimientos referidos... y por su actitud pasiva de no adoptar las medidas adecuadas y necesarias para proteger los derechos del demandante al disfrute de su domicilio y al respeto de su vida privada y familiar», FJ 6. Un comentario a ésta lo realiza S. GonZÁLeZ-VARAs IBÁÑEz, «El ruido: la Sentencia TSJ de Valencia de 7 de marzo de 1997», REALA n. ${ }^{\circ} 276,1998$, pp. 233 y ss.
} 
Por su parte, la representación letrada del Ayuntamiento demandado, primero, manifiesta que el recurso de amparo interpuesto no es de naturaleza mixta por lo que el examen del Tribunal debe circunscribirse a las alegadas vulneraciones de los artículos 14 y 24 de la CE; segundo, señala una serie de causas de inadmisión en los términos expuestos en el antecedente 9 de la Sentencia, y tercero, subsidiariamente y para el caso de que no fueran admitidas las causas de inadmisión indicadas, se opone a las alegaciones de fondo en los términos reflejados en el citado antecedente 9.

\section{LA POSICIÓN DEL MINISTERIO FISCAL}

El Ministerio Fiscal (en adelante, MF) en el procedimiento seguido ante el TSJCV solicitó la estimación de la demanda ${ }^{11}$. Y en el procedimiento de amparo iniciado ante el TC mantuvo la siguiente tesis: primero, considera que el presente recurso de amparo merece la calificación de mixto, lo que, consecuentemente, supone que el TC entienda de las vulneraciones de derechos fundamentales alegadas respecto tanto de la Sentencia del TSJCV como del Ayuntamiento de Valencia; segundo, rechaza las causas de inadmisibilidad planteadas por la representación letrada de la Administración demandada; tercero, no aprecia vulneración del artículo 14 de la CE; cuarto, tampoco aprecia vulneración del artículo 24 de la $\mathrm{CE}$, antes al contrario, considera que la alegada falta de adecuada motivación de la Sentencia no debe situarse en los cánones de dicho precepto sino en el ámbito de los artículos 15 y 18 de la $\mathrm{CE}{ }^{12}$; quinto, entiende que existe conculcación del artículo 18 de la $\mathrm{CE}$ y, consecuentemente, procedería la estimación del recurso de amparo por infracción de este precepto, toda vez que, en el caso enjuiciado, valorando conjuntamente los hechos probados «debe estimarse acreditada la prolongación en el tiempo de una situación de degradación ambiental en la zona, que perjudica a la calidad de vida de los vecinos y debe conllevar un traslado de la carga de la prueba sobre la concreta afección al domicilio de la demandante a la Administración demandada» ${ }^{13} ; \mathrm{y}$, sexto, mantiene que el ruido puede poner en

\footnotetext{
11 Antecedente 2, letra e).

${ }^{12}$ En este sentido, mantiene el MF, que los eventuales defectos en que hubiera podido incurrir la Sentencia impugnada afectan a la sustantividad de los derechos fundamentales que la Sala debió ponderar, dada la motivación reforzada que exigen las cuestiones relacionadas con los derechos fundamentales (Antecedente 10).

13 «... la inviolabilidad del domicilio podría quedar afectada si el medio ambiente circundante hace imposible la vida en su interior, tal y como resulta de la doctrina del Tribunal Europeo de Derechos Humanos (en particular, casos López Ostra contra España y X e Y contra Holanda). A partir de esta doctrina el Ministerio Fiscal solicitó una ampliación del concepto constitucional de domicilio» (Antecedente 10).
} 
peligro el derecho consagrado en el artículo 15 de la $\mathrm{CE}$, situación ésta que no se produce en el presente caso por la intensidad del ruido acreditado.

\section{FUNDAMENTOS DE DERECHO}

1. Antes de entrar en el fondo del asunto el TC desestima las causas de inadmisión alegadas por la representación letrada del Ayuntamiento de Valencia y, de acuerdo con la tesis mantenida por el MF, conviene en calificar el recurso de amparo planteado como mixto ${ }^{14}$, lo que le va a permitir conocer de las vulneraciones de derechos fundamentales alegadas frente tanto a la actuación (omisión) de la citada Corporación local como a la Sentencia del TSJCV.

2. Seguidamente, y en relación con los preceptos ${ }^{15}$ constitucionales que la recurrente alega han sido infringidos por el Ayuntamiento de Valencia, el TC circunscribe su estudio a los artículos 15 y 18.1 y 2 , es decir, a si ha habido vulneración de los derechos a la vida, a la intimidad y a la inviolabilidad del domicilio, y ello sobre la base de los conceptos de «dignidad de la persona» $\mathrm{y}$ «libre desarrollo de la personalidad» (art. 10.1 de la $\mathrm{CE}$ ) que han de presidir cualquier interpretación que de los derechos fundamentales se realice. Si bien es cierto que el Tribunal, cuando expone en «apretada síntesis» su doctrina sobre los citados artículos 15 y 18.1 y 2, circunscribe dichos conceptos al ámbito de los derechos a la intimidad y a la inviolabilidad del domicilio, aun cuando con carácter general establece que están orientados ${ }^{16}$ a otorgar plena efectividad a los derechos fundamentales contemplados en ambos preceptos.

3. El Tribunal, tras hacer mención en «síntesis» a la doctrina constitucional establecida hasta ese momento sobre el contenido y alcance de los derechos consagrados en los artículos 15 y 18.1, conviene en la necesidad de ampliar su ámbito de protección. Y, en este sentido, establece que «se hace imprescindible asegurar su protección no sólo frente a las ingerencias ya mencionadas, sino también frente a los riesgos que puedan

\footnotetext{
14 Vid. M. Gámez Mejías, «La relevancia...», cit., p. 60, y M. Pulido Quecedo, «Sobre la defensa...», cit., p. 10.

15 Artículos 9, 10, 14, 15, 17, 18, 19, 33.3, 39.1, 43, 45 y 47 de la CE.

${ }^{16}$ Respecto de «el libre desarrollo de la personalidad», y en relación con los derechos contemplados en los artículos 15 y 18.1 y 2 , se dice en esta S. que «estos derechos han adquirido también una dimensión positiva en relación con el libre desarrollo de la personalidad, orientada a la plena efectividad de estos derechos fundamentales» (FJ 5).
} 
surgir en una sociedad tecnológicamente avanzada», señalando, a renglón seguido, que a dicha realidad ha sido sensible el Tribunal Europeo de Derechos Humanos (en adelante, TEDH) en Sentencias de 21 de febrero de 1990, 9 de diciembre de 1994 y 19 de febrero de 1998.

4. Expresado lo anterior, el TC aborda el estudio de la incidencia del ruido en los derechos fundamentales contemplados en los artículos $15 \mathrm{y}$ 18.1 y 2 de la CE. Es decir, establece la doctrina general que ha de ser de aplicación para el caso concreto objeto de enjuiciamiento, y que vamos a sintetizar en los siguientes puntos:

A) Considera el ruido como un factor psicopatógeno, fuente permanente de perturbación de la calidad de vida de los ciudadanos, otorga plena validez científica a las directrices establecidas por la Organización Mundial de la Salud (en adelante, OMS) sobre el ruido ambiental, y destaca los efectos señalados en aquéllas que este agente contaminante del ambiente puede producir sobre la salud física y mental de las personas.

B) Se hace eco de la doctrina establecida por el TEDH en las Resoluciones mencionadas en el punto anterior y de su valor en virtud del artículo 10.2 de la $\mathrm{CE}$, pero considera que ello no puede suponer una traslación «mimética» de la referenciada doctrina que ignore las diferencias normativas existentes entre la CE y el Convenio Europeo de Derechos Humanos (en adelante, $\mathrm{CEDH}$ ).

C) El derecho a la integridad física y moral. Establece el Tribunal que hay vulneración de este derecho «cuando una exposición continuada a unos niveles intensos de ruido ponga en grave peligro la salud de las personas». No todo supuesto de riesgo o daño implica una vulneración del citado derecho, sino «cuando los niveles de saturación acústica que deba soportar una persona, a consecuencia de una acción u omisión de los poderes públicos se ponga en peligro grave e inmediato la salud». En estos casos podrá quedar afectado el derecho garantizado en el artículo 15 de la CE.

D) El derecho a la intimidad personal y familiar y a la inviolabilidad del domicilio. El TC entrelaza y condiciona los conceptos de intimidad personal, libre desarrollo de la personalidad e inviolabilidad del domicilio. La producción de ruidos va a constituir una vulneración del derecho a la intimidad personal y familiar cuando: a) afecte al ámbito domiciliario, b) impida o dificulte gravemente el libre desarrollo de la personalidad, y c) los niveles de ruidos puedan objetivamente calificarse como evitables, insoportables y prolongados. De este modo, entendemos que no hay con- 
culcación del derecho a la intimidad personal y familiar si el ruido no se ha experimentado en el domicilio y, además, en este caso, cuando afecte al libre desarrollo de la personalidad ${ }^{17}$. Lo que significa, a su vez, que este ámbito, el referido al libre desarrollo de la personalidad, sólo va a encontrar amparo frente al ruido cuando el sujeto afectado lo experimente en su domicilio, en los demás casos no.

5. Expuesta la doctrina relacionada en el punto anterior, el Tribunal entra en el análisis concreto de la cuestión consistente en si el nivel de ruido padecido por la recurrente en su domicilio vulnera los derechos fundamentales reconocidos en los artículos 15 y 18.1 y 2 de la CE. Pero con carácter previo el TC pone de manifiesto nuevamente que en el análisis de esta cuestión se va a ceñir a las alegaciones relativas a los citados preceptos constitucionales ${ }^{18}$, y no se va a pronunciar sobre la calidad de vida existente en el entorno urbano del domicilio de la actora, es decir, no va a entrar a conocer de las alusiones efectuadas por aquélla y el MF relativas al medio ambiente circundante, al tratarse de una cuestión reconducible, en su caso, a la esfera propia del artículo 45 de la CE.

Establecido lo anterior, en relación con la vulneración del derecho a la integridad física (art. 15), considera el Tribunal que de las pruebas practicas no se puede imputar la dolencia alegada por la demandante al ruido denunciado, toda vez que el único documento que se presenta para acreditar este extremo es un parte de consulta y hospitalización del Servicio Valenciano de Salud donde se hace constar que la actora ha padecido insomnio, pero no se precisa ni el período de tiempo de tal padecimiento ni la causa del mismo; por ello tal dolencia no se puede imputar al ruido, dice literalmente el Tribunal, «cuya intensidad ni tan siquiera se ha acreditado». Y respecto a la vulneración del derecho a la intimidad personal e inviolabilidad del domicilio (art. 18), dice el Tribunal que los alegatos formulados en este sentido no han resultado probados ya que la recurrente no ha acreditado el nivel de ruidos existente en el interior de su vivienda ${ }^{19}$, requisito éste indispensable para poder apreciar la infracción de

\footnotetext{
${ }^{17}$ Dice, literalmente, el TC: «podemos concluir que una exposición prolongada a unos determinados niveles de ruido, que puedan objetivamente calificarse como evitables e insoportables, ha de merecer la protección dispensada al derecho fundamental a la intimidad personal y familiar, en el ámbito domiciliario, en la medida en que impidan o dificulten gravemente el libre desarrollo de la personalidad, siempre y cuando la lesión o menoscabo provenga de actos u omisiones de entes públicos a los que sea imputable la lesión producida» (FJ 6).

18 Cfr. nota 15.

19 Sobre este extremo dice la S.: «no ha acreditado la recurrente ninguna medición de los ruidos padecidos en su vivienda que permita concluir que, por su carácter prolongado e insoportable, hayan podido afectar al derecho fundamental para cuya preservación solicita el amparo. Por el contrario,
} 
aquel precepto constitucional. En virtud de lo anterior, por falta de pruebas, el TC deniega el amparo solicitado frente a la actuación (omisión) del Ayuntamiento de Valencia, no considerando acreditado, en este sentido, que la lesión alegada por la recurrente sea real y efectiva.

6. Por último, el TC desestima los motivos de inconstitucionalidad alegados frente a la Sentencia del TSJCV objeto también del presente procedimiento de amparo. Frente a la citada resolución se alegó que vulneraba el artículo 24.1 de la CE por no estar suficientemente motivada y haber incurrido el Órgano jurisdiccional autor de la misma en incorrecta valoración de la prueba. Ninguno de estos alegatos han sido apreciados por el TC tal y como razona en el FJ 8 de la Sentencia. De igual modo, se argumenta que la resolución judicial recurrida en amparo vulnera el artículo 14 de la CE, al separarse, el TSJCV, sin argumentación suficiente, del criterio establecido en una Sentencia dictada con anterioridad ${ }^{20}$. El Tribunal desestima igualmente este alegato al considerar que entre una y otra Sentencia del TSJCV se observan diferencias de orden temporal y geográfico y, además, en la recurrida en amparo la pretensión se desestima por falta de pruebas.

\section{FALLO}

El TC desestima el recurso de amparo. Desestima las alegaciones y motivos formulados tanto contra la actuación por omisión del Ayuntamiento de Valencia como frente a la Sentencia del TSJCV. En el primer caso, insistimos, el Tribunal rechaza las alegadas vulneraciones de los artículos 15 y 18 de la CE por falta de pruebas, es decir, por no acreditarse la realidad y efectividad de la lesión que la demandante manifiesta haber experimentado.

\section{VOTOS PARTICULARES}

A esta Sentencia se formulan dos votos particulares concurrentes por los Magistrados don Manuel Jiménez de Parga y Cabrera y don Fernando Garrido Falla, cuyo contenido exponemos a continuación:

\footnotetext{
toda su argumentación se basa en una serie de estudios sonométricos realizados en lugares distintos de su domicilio, que arrojan resultados diversos y hasta contradictorios (...), resultaba indispensable, para que este Tribunal pudiera apreciar la existencia de dicha infracción constitucional, que hubiese acreditado el nivel de ruidos existentes en el interior de su vivienda» (FJ 7).

20 Sentencia de 7 de marzo de 1997, Sala de lo Contencioso-Administrativo, Sección Tercera, del TSJCV. Vid. nota 10.
} 
1. Voto particular formulado por el Magistrado don Manuel Jiménez de Parga y Cabrera.

a) Está de acuerdo con el fallo de la Sentencia en el sentido de denegar el amparo solicitado por falta de pruebas tal y como se razona en el FJ 7.

b) No comparte el criterio seguido en la Sentencia respecto de soslayar cualquier pronunciamiento en relación con la calidad de vida y el medio ambiente circundante por tratarse de una cuestión reconducible, en su caso, al artículo 45 de la CE, negando, con ello, cualquier valor subjetivo al «derecho al medio ambiente adecuado para el desarrollo de la persona» consagrado en el citado precepto constitucional ${ }^{21}$.

c) No considera que, como se estipula en la Sentencia, para que el ruido vulnere el derecho a la integridad física consagrado en el artículo 15 de la $\mathrm{CE}$, dicho agente contaminante tenga que ser intenso y poner en grave e inmediato peligro la salud de las personas. Con este pronunciamiento, afirma el Magistrado autor de este voto particular, primero, subyace una separación entre la integridad física (art. 15) y la salud (art. 43), y, segundo, se adopta un criterio contrario al establecido, en este sentido, por la legislación europea y las directrices de la OMS, en cuya virtud bastaría con que el ruido produjera sólo consecuencias negativas para la salud. De este modo, para la vulneración del citado derecho fundamental debería bastar con que el ruido produjera cualquier efecto nocivo.

d) Y, por último no comparte el criterio adoptado en la Sentencia (FJ 6) de vincular el libre desarrollo de la personalidad al ámbito domiciliario. El libre desarrollo de la personalidad puede resultar afectado por el ruido ambiental o circundante, y no, sólo, cuando se soporte en el ámbito domiciliario.

2. Voto particular del Magistrado don Fernando Garrido Falla. Este Magistrado comparte las líneas fundamentales de la Sentencia y el fallo adoptado en la misma, pero realiza las siguientes matizaciones:

\footnotetext{
${ }^{21}$ Sobre este extremo, afirma este Magistrado: «sigo entendiendo, ..., que resulta conveniente reivindicar este contenido o componente subjetivo del artículo 45.1 CE, pues la historia demuestra, con harta frecuencia, que el Derecho evoluciona hacia la consecución de mayores cotas de bienestar y libertad gracias sobre todo a los esfuerzos de los ciudadanos que tratan de hacer valer sus derechos frente a la pasividad de los poderes públicos. Creo que este Tribunal, en el presente caso, podría haber contribuido a aportar unos instrumentos que fecundaran esa labor de lucha por el Derecho y por la mejora de la calidad de vida, que también es, no se olvide, un valor constitucional (art. $45 \mathrm{CE}) »$.
} 
a) Como quiera que la lesión de derechos fundamentales puede producirse tanto por personas de naturaleza pública como privada, y en el presente caso las fuentes productoras del ruido padecido por la recurrente son personas privadas, es importante determinar si la Administración está obligada a dispensar protección frente a vulneraciones de derechos fundamentales cuando éstas son producidas, como ocurre en el presente caso, por personas no de naturaleza pública. En estos casos, cuando la actividad productora de ruidos esta sujeta a autorización o licencia administrativa, la Administración está obligada a actuar «cuando la agresión a los derechos fundamentales alcanza un determinado nivel de gravedad». Cuestión ésta deficientemente clarificada en la Sentencia, y de especial importancia para determinar el nexo causal entre la lesión producida y la inactividad de la Administración.

b) Respecto del derecho a la integridad física, matiza este Magistrado, debe abarcar aquellos supuestos en los que, quien produce los ruidos, no exista intención reflexiva de producir tal perturbación. En relación con la intimidad personal y familiar, participa de cuanto se dice en la Sentencia pero debiendo concebir la agresión a la intimidad no sólo como la publicatio de lo que pertenece a nuestra «privacidad», «sino como el derecho a desarrollar nuestra vida privada sin perturbaciones e injerencias que sean evitables y no tengamos el deber de soportar», debiendo alcanzar la efectividad de este derecho nuestro descanso y la tranquilidad mínima que exige el desempeño de nuestro trabajo intelectual. Y, por último, respecto de la inviolabilidad del domicilio, se afirma que la saturación acústica potencia la vulneración de la intimidad personal y familiar cuando la perturbación se experimenta en el propio domicilio, lo que da pie a entender que puede haber vulneración de dicha intimidad por esta causa sin que la perturbación se experimente en el domicilio 22 ; pudiendo ocurrir que los ruidos sean tan insoportables que obliguen al dañado a cambiar de domicilio en cuyo caso se produciría una doble vulneración de derechos fundamentales: el derecho a la inviolabilidad del domicilio (art. 18.1) y el derecho a la libre elección del domicilio (art. 19).

\section{CONSIDERACIONES FINALES}

1. El ruido es un agente contaminante del medio ambiente y perturbador de la salud de las personas. Es una forma de energía mecánica que

${ }^{22}$ Aunque a renglón seguido dice que «como regla - y desde luego en el caso del presente recurso- intimidad y domicilio, frente a agresión acústica, constituyen una unidad inescindible». 
incide negativamente en el estado físico y psíquico del ser humano ${ }^{23}$, le impide la tranquilidad y el descanso, y menoscaba su capacidad laboral. También, en las recientes leyes de protección de la naturaleza se ha dejado constancia de su influencia negativa en el desarrollo de las especies de la flora y fauna silvestres ${ }^{24}$.

Pero, siendo el ruido un sector integrante del ambiente, la relevancia de la contaminación acústica radica, en gran medida, en los efectos nocivos y molestos que produce en el entorno vital de las personas, en «la salud humana» en el sentido más amplio de la expresión. La importancia del ruido y, por ende, la necesidad de adoptar medidas sobre esta materia tiene lugar por la gravedad de los efectos que produce sobre la salud de las personas. Posiblemente, sea éste uno de los sectores del ambiente donde, con mayor facilidad, pueda apreciarse la relación existente entre este último concepto y la salud humana ${ }^{25}$, y, consecuentemente, donde pudiera adquirir mayor justificación esa «cierta concepción antropocéntrica del medio ambiente» que la doctrina penal del TS ${ }^{26}$ ha apreciado en el artículo 45 de la CE. En especial la protección frente al ruido se justifica en la salvaguarda, más que de otros sectores del ambiente, de derechos, bienes, valores y principios ligados al hombre. Algunos relacionados íntimamente con sus posibilidades reales de existencia como su salud, y, otros, no tanto, pero no menos importantes como la dignidad, la intimidad personal y familiar, el desarrollo de su personalidad y la calidad de vida ${ }^{27}$. Derechos, valores y principios estos a cuyo fin y realización debe estar orientada la actuación de los poderes públicos, garanti-

\footnotetext{
${ }^{23}$ Vid. el anexo 4 del Libro Verde de la Comisión Europea sobre política futura de lucha contra el ruido, Documento COM(96) 540 final, Bruselas, 4 de noviembre de 1996.

${ }^{24}$ El artículo 38.4 de la Ley 4/1989, de 27 de marzo, de Conservación de los Espacios Naturales y de la Flora y Fauna Silvestres, tipifica como infracción administrativa «la emisión de ruidos que perturben la tranquilidad de las especies en espacios naturales protegidos». Vid. L. MARTín-RetorTILLO BAQUER, «El ruido en la reciente jurisprudencia», RAP, n. ${ }^{\circ} 125,1991$, p. 324, y M. URIARTE Ricote, «El desarrollo normativo de la protección frente al ruido en la Comunidad Autónoma Vasca», RVAP, n. ${ }^{\circ} 34,1992$, p. 290
}

${ }^{25}$ Sobre la relación entre salud y medio ambiente vid., entre otros trabajos, D. I. LoPERENA Rota, «La protección de la salud y el medio ambiente adecuado para el desarrollo de la persona en la Constitución», en Estudios sobre la Constitución Española. Homenaje al Profesor Eduardo García de Enterría, Tomo II, Ed. Civitas, Madrid, 1991, pp. 1455 y ss.

${ }^{26}$ SS de 11 de marzo de 1992, 26 de septiembre de 1994 y 17 de enero de 1999. Cfr. N. J. DE LA Mata Barranco, Protección Penal del Ambiente y Accesoriedad Administrativa, Ed. Cedecs, Barcelona, 1996, pp. 51 y ss.

${ }^{27}$ En particular, sobre la «calidad de vida», cfr. R. MARTín MATEO, «La calidad de vida como valor jurídico», en Estudios sobre la Constitución Española. Homenaje al Profesor Eduardo García de Enterría, Tomo II, Ed. Civitas, Madrid, 1991, pp. 1437 y ss., y J. Rodríguez-Arana MuÑoz, «Medio ambiente y calidad de vida: objetivos constitucionales», $R D A$, n. ${ }^{\circ} 16,1996$, pp. 36-48. 
zando un conjunto de condiciones mínimas en el entorno donde el hombre se desenvuelve ${ }^{28}$. Es evidente que aquéllos resultan afectados cuando la contaminación acústica circundante alcanza determinados niveles.

2. No obstante la gravedad de los efectos del ruido sobre el hombre, es lo cierto que nos hallamos ante un sector del ambiente insuficientemente regulado, si bien sería injusto no reconocer la importante labor que en este ámbito están realizando las CC.AA. ${ }^{29} \mathrm{y}$ las Corporaciones Locales ${ }^{30}$ dictando normas de notable sustantividad, y ello, además de en el ejercicio de sus competencias sobre esta materia, ante la inexistencia a nivel estatal de una norma básica de ruidos que bien hubiera podido dictar el Estado en virtud de sus competencias en materia de medio ambiente y salud pública ${ }^{31}$.

Como es sabido, en el momento actual, el ruido puede generar controversias con repercusión en los cuatro órdenes jurisdiccionales existentes en nuestro sistema procesal. Así:

A) En el ámbito civil, con carácter general, y en el marco de las relaciones de vecindad, el Código Civil ${ }^{32}$ (en adelante, CC) faculta al titular de derechos reales, cuando éstos pudieran resultar afectados, para ejercer ante los tribunales de este Orden jurisdiccional acciones ${ }^{33}$ orientadas a evitar la producción de daños y, en su caso, a la reparación de los mismos. Los titulares «vecinos» ${ }^{34}$ de derechos reales podrán ejercer las mencionadas acciones cuando se vean perturbadas sus relaciones como consecuencia de la generación de ruidos, y frente a los generadores de éstos.

\footnotetext{
28 Vid. supra.

${ }^{29}$ Así, entre otras, las CC.AA. relacionadas a continuación han dictado disposiciones propias en materia de ruidos: Andalucía (Ley 7/1994, de 18 de mayo, de Protección Ambiental, BOJA n. ${ }^{\circ}$ 79, de 31 de mayo, desarrollada en materia de ruidos por Decreto 74/1996, de 20 de febrero, por el que se aprueba el Reglamento de Calidad del Aire, BOJA n. ${ }^{\circ} 30$, de 7 de marzo, desarrollado, a su vez, por la Orden de la Consejería de Medio Ambiente de 23 de febrero de 1996, BOJA n. ${ }^{\circ} 30$, de 7 de marzo); Extremadura (Decreto 19/1997, de 4 de febrero, de Reglamentación de Ruidos y Vibraciones, $D O E$ n..$^{\circ} 18$, de 11 de febrero); y Galicia (Ley 7/1997, de 11 de agosto, de Protección contra la Contaminación Acústica, $D O G$ n. ${ }^{\circ}$ 159, de 20 de febrero, desarrollada mediante Decreto 150/1999, de 7 de mayo, por el que se aprueba el Reglamento de Protección contra la Contaminación acústica, $D O G$ n. ${ }^{\circ} 100$, de 27 de mayo).

${ }^{30}$ A través del dictado de Ordenanzas.

31 Artículos 149.1.16 y 23 de la CE.

32 Artículos 590, 1.902, 1.908 y demás concordantes.

33 Acción negatoria y acción de responsabilidad civil extracontractual por daños.

34 Vid. C. Conde-Pumpido Tourón, «La responsabilidad civil por daños al medio ambiente», RDA, n. ${ }^{\circ} 5,1990$, pp. 12-19.
} 
También, el artículo 27.2.e) de la LAU ${ }^{35}$, para el caso de fincas urbanas sujetas a esta norma, habilita al arrendador para resolver el contrato de arrendamiento «cuando en la vivienda tengan lugar actividades molestas, insalubres, nocivas, peligrosas o ilícitas». De igual modo, el artículo 7.2 de la LPH ${ }^{36}$ prohíbe al ocupante o propietario de una finca sometida al régimen que establece la citada Ley la realización de «actividades prohibidas en los estatutos... o que contravengan las disposiciones generales sobre actividades molestas, insalubres, nocivas, peligrosas o ilícitas» ${ }^{37}$.

B) En el ámbito del Derecho penal, el Código Penal de 1995 (en adelante, CP95), bajo la rúbrica «de los delitos contra los recursos naturales y el medio ambiente», en el artículo 325 tipifica como delito la provocación o realización de ruidos y vibraciones en la atmósfera que puedan perjudicar «gravemente» el equilibrio de los sistemas naturales o la salud de las personas. Sin embargo, en el sistema de faltas ${ }^{38}$ que contempla la citada norma no se establece tipificación alguna donde la conducta prohibida resulte ser la producción de ruidos. Tampoco se contemplan figuras de esta naturaleza donde, tal y como ocurría en la legislación anterior ${ }^{39}$, con mayor facilidad pudieran tener encaje situaciones generadoras de contaminación acústica.

Ni que decir tiene que la contemplación expresa de los ruidos y vibraciones en el citado artículo 325 del CP95 ha supuesto un avance incuestionable en la protección del medio ambiente. Pero, como ha señalado la profesora ALONSO GARCÍA ${ }^{40}$, el principio de intervención mínima que rige en esta rama del Derecho, el carácter de tipo penal en blanco, y, sobre todo, la exigencia de que el riesgo de peligro sea «grave» como elemento del tipo, puede hacer poco operativo el citado precepto ante situaciones

\footnotetext{
${ }^{35}$ Ley 29/1994, de 24 de noviembre, de Arrendamientos Urbanos.

${ }^{36}$ Ley 49/1960, de 21 de julio, sobre Propiedad Horizontal, reformada por la Ley 8/1999, de 6 de abril.

37 Y faculta al Presidente de la Comunidad, a iniciativa propia o de cualquiera de los propietarios u ocupantes de las fincas de dicha Comunidad, para requerir la inmediata cesación de la citada actividad; pudiendo ejercer, si dicho requerimiento no resultara atendido, acciones judiciales en cuyo procedimiento la autoridad judicial podrá adoptar cautelarmente la cesación de la actividad prohibida y, finalmente, resolver, en la sentencia, la citada cesación, la indemnización de los daños y perjuicios causados si los hubiere, la privación del derecho al uso del inmueble durante un período no superior a 3 años, y declarar extinguidos todos los derechos relativos al inmueble si el infractor no fuese el propietario, así como su inmediato lanzamiento.
}

${ }^{38}$ Artículos 617 y ss. del CP95.

39 Vid. C. Alonso García, «La contaminación acústica», en Lecciones de Derecho del Medio Ambiente, obra dirigida por L. Ortega Álvarez, Ed. Lex Nova, Valladolid, 1998, p. 319.

40 Vid. supra. 
que con cierta frecuencia se producen en la sociedad actual y que, en nuestra opinión, sí revisten «gravedad» para el entorno del hombre: los ruidos «evitables» ${ }^{41}$ que afectan a su tranquilidad y descanso.

C) En el ámbito del Derecho administrativo, el ruido ha sido afrontado de forma parcial y sectorializada atendiendo, fundamentalmente, a las fuentes productoras ${ }^{42}$ de esta modalidad de contaminación, tales como los establecimientos públicos, las industrias, los medios de transporte, etcétera. Los mecanismos previstos por esta rama del Derecho se circunscriben a medidas de intervención como sujeción a autorización o concesión administrativas, homologación, exigencia de medidas correctoras, inspección e imposición de sanciones. Sin embargo, debemos advertir de que en este sector del Ordenamiento jurídico se observa una cierta laguna en aquellos casos en los que el ruido procede de comportamientos incívicos o, aun cuando no sea así, se trate de ruidos evitables que perturban la tranquilidad y el descanso de las personas. Es importante señalar en este ámbito que, tristemente en algunos casos, y afortunadamente no en todos, la indefensión o principal peligro que va a hallar el administrado para defenderse frente a las actividades ruidosas va a ser la tolerancia e inactividad de la Administración competente.

D) También, el ruido puede dar origen a controversias cuyo conocimiento y resolución ha de realizarse en sede de la Jurisdicción laboral. El ruido es un agente perturbador de la salud laboral. La normativa de esta especialidad impone obligaciones al empleador ${ }^{43}$ orientadas a salvaguardar a los trabajadores de los riesgos derivados del ruido durante la realización de la jornada laboral.

3. En la doctrina de nuestra especialidad el profesor L. MARTíN-RETORTILlo puso de manifiesto que los ruidos ilegítimos, aquellos que resultan evitables, constituyen una invasión que ataca el derecho a la inviolabilidad del domicilio y hiere la intimidad personal ${ }^{44}$. Mantiene el

\footnotetext{
41 Véase el punto 3 de estas Consideraciones Finales.

42 Sobre la regulación actual del ruido atendiendo a las fuentes que lo producen, desde la óptica del Derecho administrativo, vid. M. C. Alonso GARCíA, El régimen jurídico de la contaminación atmosférica y acústica, Ed. Marcial Pons, Madrid, 1995, pp. 210 y ss.

43 Véanse, a modo de ejemplo, y sin ánimo de exhaustividad los artículos 18.1.c) y 23.1 de la Ley 31/1995, de 8 de noviembre, de Prevención de Riesgos Laborales, y el Real Decreto 1316/1989, de 27 de octubre, sobre medidas de protección de los trabajadores frente a los riesgos derivados de su exposición al ruido.

44 L. Martín-Retortillo Baquer, «La defensa frente al ruido ante el Tribunal Constitucional», RAP n. ${ }^{\circ} 115,1988$, pp. 205-231.
} 
citado profesor que, habida cuenta de la vinculación recíproca existente entre domicilio e intimidad, este tipo de ruidos puede constituir una vulneración de los derechos a la intimidad personal y a la inviolabilidad del domicilio reconocidos en el artículo 18 de la CE, y, por ello, frente a los mismos deben ser de aplicación las garantías previstas para el citado precepto constitucional ${ }^{45}$, al resultar éste vulnerado por la producción de aquéllos. Esta posición doctrinal, prontamente, fue acogida por la Sala de lo Contencioso-Administrativo de la Audiencia Territorial de Zaragoza, de 10 de octubre de $1988^{46}$, donde en el enjuiciamiento de unas medidas adoptadas por el Ayuntamiento de la citada ciudad consistentes en la limitación de los niveles de música para determinados establecimientos públicos, considera legítima dicha medida adoptada en virtud de la técnica de la «policía de la tranquilidad» que debe garantizar el derecho de los demás administrados a no ser molestados, «y que podría incluso enlazarse con el derecho constitucionalizado en el párrafo primero del artículo 18 de la Carta Magna, que garantiza el derecho a la intimidad personal y familiar».

4. La posición doctrinal referida en el punto anterior amplía la protección jurídica frente al ruido. A partir de su divulgación científica en $1988^{47}$, y acogiendo sus planteamientos básicos, tuvo lugar una corriente jurisprudencial procedente de distintos órdenes y órganos jurisdiccionales que, en nuestra opinión, amplía, aún más, la defensa del administrado frente a la contaminación acústica. A continuación, sin ánimo de exhaustividad, dejamos constancia de algunas de estas resoluciones judiciales:

A) En el ámbito del TEDH ${ }^{48}$. En la S. de 21 de febrero de 1990 (Caso Powell y Rainer contra el Reino Unido) aun cuando el Tribunal no se pronunció sobre las reclamaciones de los demandantes por infracción de los artículos 6.1 y 8 del CEDH, sí admitió que determinados niveles de ruidos atentan contra la calidad de vida y privan a la persona afectada del disfrute de su domicilio, pudiendo vulnerar el artículo $8^{49}$ del citado

\footnotetext{
45 Artículo 53.2 de la CE.

46 Esta Sentencia ha sido comentada por L. Martín-Retortillo Baquer, «Los "ruidos evitables”», REALA n. ${ }^{\circ} 238,1988$, pp. 1275-1282.

47 Vid. nota 44.

48 Sobre algunas de las Sentencias aquí relacionadas, entre otros, pueden verse los trabajos de L. Jimena Quesada y B. S. Tomás Mallén, «El derecho al medio ambiente en el marco del Convenio Europeo de Derechos Humanos», $R G D$, marzo 1996, pp. 2136-2179, y L. Martín-Retortillo BAQUER, «El ruido de los grandes aeropuertos en jurisprudencia del Tribunal Europeo de Derechos Humanos», RVAP, n. ${ }^{\circ} 40,1994$, pp. 103-120.

49 Se dice en este precepto: «1. Toda persona tiene derecho al respeto de su vida privada y familiar,
} 
CEDH. En la S. de 9 de diciembre de 1994 (Caso López Ostra contra España), se condena al Estado español por vulneración del artículo 8 del $\mathrm{CEDH}$ al considerar que los humos, ruidos y olores que producía una actividad industrial, además de perjudicar y deteriorar la calidad de vida de los vecinos afectados, vulnera, en la persona de la demandante, el goce efectivo del derecho al respeto de su domicilio y de su vida privada y familiar ${ }^{50}$. Y, también, en la S. de 19 de febrero de 1998 (Caso Guerra y Otras contra Italia) ${ }^{51}$, ante la existencia de una instalación industrial que liberaba grandes cantidades de gas inflamable y otras sustancias nocivas como anhídrido de arsénico, canalizándose dichas emisiones a menudo hacia un pueblo habitado, considera el TEDH que las autoridades nacionales incumplieron la obligación de informar sobre los riesgos que dichas emisiones podían producir en las personas de los demandantes y de sus allegados. La forma de proceder de dichas autoridades permitió que aquéllos continuaran residiendo en el territorio del citado municipio que estuvo expuesto al peligro en caso de accidente en el recinto de la instalación industrial. Por ello, considera el Tribunal, el Estado ha fracasado en su obligación de garantizar el derecho de los demandantes a su vida privada y familiar, vulnerando, de este modo, el artículo 8 del CEDH.

B) No es abundante la jurisprudencia del TC recaída sobre ruidos. Posiblemente la Resolución de mayor trascendencia sobre esta materia sea la que constituye el objeto de este trabajo. Sin embargo, y no obstante lo anterior, conviene hacer referencia a dos pronunciamientos de este Tribunal, el primero se realiza en la S. 102/1995, de 26 de junio, donde se hace referencia de forma expresa a la «contaminación acústica» como agente perturbador del ambiente y de la salud de la población ${ }^{52}$. Y, el se-

de su domicilio y correspondencia. 2. No podrá haber injerencia de la autoridad pública en el ejercicio de este derecho, sino en tanto en cuanto esta injerencia esté prevista por la ley y constituya una medida que, en una sociedad democrática, sea necesaria para la seguridad nacional, la seguridad pública, el bienestar económico del país, la defensa del orden y la prevención del delito, la protección de la salud o de la moral, o la protección de los derechos y las libertades de los demás».

\footnotetext{
${ }^{50}$ Vulneración ésta que no ha sido impedida por las instancias administrativas nacionales competentes, y por ello se condena al Estado español.

${ }^{51}$ Si bien esta S. no se refiere a un supuesto de contaminación acústica, sino a un caso de emisión de gases y sustancias, consideramos interesante su mención aquí por cuanto que se trata de un supuesto de «inmisión», concepto éste en cuya acepción técnico-jurídica deben tener encaje los ruidos. Cfr. E. Algarra Prats, La defensa jurídico-civil frente a humos, olores, ruidos y otras agresiones a la propiedad y a la persona, Ed. McGraw-Hill, Madrid, 1995, pp. 236 y ss.

52 Se dice en esta S.: «la contaminación acústica y tantas otras manifestaciones que van desde lo simplemente incómodo a lo letal, con una incidencia negativa sobre la salubridad de la población en la inescindible unidad psicosomática de los individuos (...), la acción del hombre con riesgo para el medio ambiente se proyecta en las más variadas manifestaciones, sanitarias, biológicas, industriales...» (FJ 7).
} 
gundo, que tiene lugar en la S. 199/1996, de 3 de diciembre ${ }^{53}$, el Tribunal, de una parte, se hace eco de la doctrina del TEDH relacionada en el punto anterior estableciendo que en el presente asunto no resulta de aplicación por tratarse de una situación distinta de aquélla ${ }^{54}$, y, de otra parte, considera que el derecho contemplado en el artículo 45 ha de protegerse por los Tribunales de Justicia según lo que dispongan las leyes que lo desarrollen en virtud de lo establecido en el artículo 53.3 de la CE. A la vista de estas dos resoluciones debemos convenir que el TC, primero, considera la doble vertiente sanitaria y ambiental del ruido, segundo, no rechaza la citada doctrina del TEDH, y tercero, niega valor subjetivo al derecho reconocido en el artículo 45 de la CE y, con ello, la posibilidad de utilizar esta vía cuando la vulneración del citado precepto tenga lugar como consecuencia de la producción de ruidos.

C) Por lo que se refiere a la jurisprudencia del TS procedente de la Sala de lo Contencioso-Administrativo, especial mención merece el Auto de 11 mayo de $1989^{55}$, donde se deja constancia de la doble afección que produce el ruido sobre el medio ambiente y la salud, haciendo referencia expresa al descanso cuando dice que «como poder público que también es, este Tribunal está conminado constitucionalmente a velar por ese medio ambiente lo que supone velar también por la salud (art. 43 de la Constitución) porque la contaminación acústica no sólo es que impide el descanso a los que habitan en viviendas cercanas sino que perjudica la salud de todos los que se ven sometidos a la incidencia de un número excesivo de decibelios». También, en la S. de 7 de noviembre de 1990, el Tribunal desestima la indemnización pretendida por el titular de un establecimiento público frente al Ayuntamiento ${ }^{56}$, argumentando, en este sentido, que el recurrente tenía que saber que siendo su local al aire libre, el derecho al medio ambiente adecuado de todos (que implica, entre otras cosas, un

\footnotetext{
${ }^{53}$ Dictada como consecuencia de un recurso de amparo interpuesto contra el archivo de las actuaciones seguidas por presunto delito ecológico por emisión de gases y sustancias procedentes de una instalación industrial.

54 En este sentido, se dice en la S. citada: «en el presente caso,... no se trata de reaccionar por la vía contencioso-administrativa contra la inactividad de las Administraciones competentes, sino de pretender que se impongan penas a determinadas personas por unos hechos conceptuados como delito. Por consiguiente, no puede aceptarse la invocación que se hace en la demanda de amparo de la doctrina de la Sentencia del TEDH López Ostra, que fue pronunciada para enjuiciar una situación dispar a la actual» (FJ 4).

${ }^{55}$ La STSJ de Baleares, Sala de lo CA, de 29 de julio de 1999, ha establecido respecto de este Auto que: «al efectuar una comparación entre el derecho a la actividad empresarial (art. 38 de la CE) y el derecho al descanso y a la salud (art. $43 \mathrm{CE}$ ), acabó concluyendo la prevalencia de este último».

56 Y ello, con fundamento en la decisión de la citada Administración consistente en la reducción del nivel de emisión acústica permitida.
} 
medio ambiente acústicamente no contaminado) no puede verse abatido en su beneficio, toda vez que los vecinos tienen derecho al descanso y a la salud, y uno y otro se ven conculcados si no se respeta la moderación en la música ambiental ${ }^{57}$. Por su parte, tanto en el Auto citado en primer lugar como en las SS. de 20 de septiembre de 1994 y 6 de febrero de 1996, se plantean cuestiones referidas al conflicto de intereses que pudieran surgir entre derechos constitucionalmente reconocidos tales como el medio ambiente (art. 45), el derecho al ejercicio de una actividad industrial (art. 38) y el derecho de propiedad (art. 33).

La jurisprudencia civil del TS, tal y como se ha expuesto en el punto 2 de estas Consideraciones Finales, con fundamento en los preceptos allí relacionados, ha estimado la procedencia de acciones ${ }^{58}$ orientadas a evitar y, en su caso, a reparar daños derivados de conductas ruidosas ${ }^{59}$, con el fin de salvaguardar derechos, fundamentalmente, de naturaleza real. Sin embargo, en este ámbito donde el bien jurídico protegido por excelencia es el derecho de propiedad en el marco de las relaciones de vecindad, merece la pena hacer referencia a dos resoluciones cuya argumentación jurídica, entendemos, va más allá de los límites del indicado derecho. Así, en la S. de 16 de enero de 1989, ante la alegación consistente en que la contaminación ambiental representa un peligro latente para las vidas humanas por el riesgo notorio de producir graves dolencias a las personas, lo que, a su vez, integra un perjuicio, al menos de orden moral, afirma el Tribunal que dicho alegato «no deja de presentar cierto interés», pero no puede ser valorado y considerado al no haber sido planteado en el momento procesal oportuno. Y, en la S. de 2 de febrero de 2001, y ante un supuesto de reclamación de daños y perjuicios ocasionados por una instalación industrial por la producción de ruidos y polvos, el TS eleva la cuantía resuelta por el Tribunal a quo al considerar que éste no ha tenido en cuenta como elemento indemnizatorio la alegada disminución de vida

\footnotetext{
57 Se dice literalmente en esta S.: «el grave deterioro del medio ambiente en todos sus aspectos ha transformado el problema de su conservación en un problema esencial, cuya solución es urgente e ineludible, pues muchos de sus aspectos afectan a la supervivencia, y otros, como el de la contaminación acústica a la salud y a la convivencia civilizada. Es notorio que se han elevado voces autorizadas procedentes del campo de la medicina denunciando cómo afecta al oído y al corazón el sometimiento continuado del individuo a un excesivo número de decibelios. Y lo único que aquí hay que lamentar es que todavía haya poderes públicos que manifiesten una cierta pasividad en la adopción de medidas eficaces en defensa contra las múltiples agresiones al medio ambiente que se dan todos los días y en todas las partes».

58 Vid. nota 33.

59 Vid. sobre este tema, entre otros trabajos, E. Algarra Prats, La defensa jurídico-civil..., op. cit., pp. 288 y ss., y M. A. PARRA LuCÁN, La protección del medio ambiente, Ed. Tecnos, Madrid, 1992, pp. 105-108, y J. Santos BRiz, La responsabilidad civil. Derecho sustantivo y procesal, vol. 2, quinta edición, Ed. Montecorvo, Madrid, 1989, pp. 781 y ss.
} 
humana ${ }^{60} \mathrm{y}$ el deterioro medioambiental continuado que los recurrentes han experimentado. Elementos éstos que deben resultar subsumibles en el ámbito de la responsabilidad extracontractual del artículo 1.902 del $\mathrm{CC}$, y que los tribunales deben tener en cuenta a efectos indemnizatorios.

En el ámbito penal, y desde que se tipificara el delito ecológico introduciendo en 1983 el artículo 347 bis en el Código Penal de 1973, en las resoluciones que hemos manejado no hemos hallado referencias expresas a la contaminación acústica que merezcan la pena traer aquí a colación. Sin embargo, es importante señalar que el TS, en SS. de 30 de noviembre de 1990 y 11 de marzo de 1992, ha resaltado el concepto de «calidad de vida» en la determinación del bien jurídico protegido en esta figura delictiva: el equilibrio de los sistemas naturales y la salud de las personas.

D) Pero será en el ámbito de la jurisprudencia menor, de los Tribunales Superiores de Justicia (en adelante, TSJ) y de las Audiencias Provinciales (en adelante, AP), y en consonancia con lo expuesto al comienzo de este punto, donde con mayor facilidad resulta apreciable esa ampliación de la protección jurídica del administrado frente al ruido, lo que, en nuestra opinión, procura una interpretación de las normas reguladoras de este sector ambiental acorde con el contexto y la realidad social del tiempo en que han de ser aplicadas ${ }^{61}$. Respecto de las resoluciones de esta clase que hemos manejado interesa destacar las siguientes cuestiones:

a) Inactividad administrativa. Afortunadamente no siempre, queda constancia suficiente de esta actitud de las Administraciones públicas competentes frente a los problemas derivados del ruido. Sobre todo en el ámbito local donde no son infrecuentes los supuestos en los que los Ayuntamientos se mantienen pasivos y tolerantes ante el funcionamiento de establecimientos públicos que emiten ruidos por encima de lo legislado, unas veces, estando autorizados y, otras veces, sin estarlo, es decir, funcionando clandestinamente. Esta forma de proceder ha sido calificada como impropia «de un Ayuntamiento democrático,... haciéndole dar a la Institución una mala imagen que proyecta a los ciudadanos una situación de indefensión ante los poderes públicos» ${ }^{62}$. En otros supuestos, en lo

\footnotetext{
60 Debemos entender, a la vista del FJ 4 de la Sentencia recurrida, que dicho elemento no ha sido tenido en cuenta a efectos indemnizatorios por no «llegar a ocasionar enfermedad somática objetivada...».

61 Artículo 3 del CC.

62 Voto particular formulado por el Magistrado don Edilberto José Narbón Laínez a la STSJ de Valencia, Sala de lo CA, de 29 de junio de 1998, donde se dice: «las reclamaciones vecinales comienzan en 1993 con total y absoluta pasividad del Ayuntamiento de Valencia, se agrava la situación en
} 
que sí ha habido auténtica actuación positiva de la Administración pero con resultados adversos para los vecinos, los Tribunales no han dudado en calificar dicha actuación como arbitraria y como «desprecio manifiesto de la legalidad» ${ }^{63}$. Esta jurisprudencia ha hecho especial hincapié en la efectividad y decisión con que han de actuar los municipios ante los problemas derivados del ruido, y ello al estar en juego «valores innegables» de los ciudadanos tales como la calidad de vida ${ }^{64}$, y, en este sentido, se subraya que la Administración debe hacer uso de todos los medios legales de que dispone ${ }^{65}$, no bastando «cualquier» actuación sino que ésta ha

1995 con sucesivas reclamaciones vecinales y noticias aparecidas en la prensa, incluso dando una pésima imagen impropia de un Ayuntamiento Democrático, cuando los vecinos acuden al Defensor del Pueblo, el Ayuntamiento se niega a contestarle, haciéndole dar a la Institución una mala imagen que proyecta a los ciudadanos una situación de indefensión ante los Poderes Públicos».

${ }^{63}$ En STSJ de Andalucía, Sala de lo CA (Sevilla), de 29 de marzo de 2001, así se califica el acuerdo de un Ayuntamiento que otorgó a determinados establecimientos públicos «autorización provisional» de funcionamiento mientras se tramitaba y resolvía el expediente administrativo ordinario para la obtención de la licencia municipal de apertura. Dichos establecimientos, durante el período de «funcionamiento provisional», fueron denunciados por los vecinos por sobrepasar los límites admitidos de ruidos.

${ }^{64}$ Así, en STSJ de Baleares, Sala de lo CA, de 24 de septiembre de 1996, se dice: «ciertamente, sobre los problemas derivados del ruido, la Administración debe actuar con medidas preventivas y de control, pero también, sancionadoras, en defensa de unos valores ciudadanos innegables y de un bien central en lo que a calidad de vida se refiere. (...). Hoy en día ya no debe quedar duda alguna de que en el control y eliminación del ruido que excede de lo previsto, la actuación administrativa municipal ha de tener un papel bien efectivo a la hora de vigilar y garantizar el correcto funcionamiento de establecimientos que cayeran en excesos». De igual modo, en S. de 29 de julio de 1999, Sala de lo CA, de este mismo Tribunal, se afirma: «este Tribunal en S. de 27 de junio de 1997 ya recordó que "en cuestión de ruidos en el ambiente urbano no debe olvidarse que en nuestro sistema, en el sistema de libertades públicas, el respeto por los derechos de los demás exigen una atención sobreañadida. (...), de modo que al poder público, en especial al más cercano, al municipal, en tanto que responsable, le es exigible redoblar la vigilancia. De no ser así, si nada potencialmente eficaz se hace para que así sea, quien insoslayablemente perderá será el más débil, quien espera con paciencia una solución que nunca parece llegar; perderá pues, el ciudadano"». Esta S. ha sido comentada por P. Acosta Gallo, «Ruidos nocturnos por afluencia masiva de público a locales de ocio e intervención municipal (la STSJ de I.B. de 29 de julio de 1999)», REALA n. ${ }^{\circ} 282,2000$, pp. 283-296.

${ }^{65}$ En STSJ de Andalucía, Sala de lo CA (Sevilla), de 29 de octubre de 2001, se afirma que: «en efecto no basta con regular mediante las oportunas ordenanzas la protección del medio ambiente, la prohibición de venta de alcohol fuera de los establecimientos que tengan licencia para ello, la limpieza en los lugares públicos, sino que con los medios adecuados hacer efectivas dichas Ordenanzas impidiendo que se sobrepasen los límites de emisión de ruidos procediendo al cierre de los establecimientos que lo incumplan e incluso dispersando las concentraciones de jóvenes cuando sobrepasan dichos límites. No se trata de ejercer una represión policial, sino dentro de los límites de dicha función denunciar una y otra vez las infracciones administrativas, incomodar y disuadir sin descanso a los jóvenes en sus comportamientos y no favorecer mediante cortes de tráfico y vallas dichas concentraciones porque los derechos de los jóvenes a expresarse y reunirse encuentran sus límites en los derechos de los demás ciudadanos a la libre circulación, al descanso y a la propia vida entendida en un sentido amplio no sólo físico, que se ven menoscabados al no adoptar la Administración demandada las medidas adecuadas y suficientes para paliar al menos en parte los efectos negativos concretrados en el presente proceso». 
de ser «suficiente» para poner fin a los problemas ocasionados por el ruido ${ }^{66}$. Por último, dejar constancia que la inactividad de la Administración frente a los ruidos ilegales es generadora de responsabilidad patrimonial ${ }^{67}$ lo que, consecuentemente, conlleva la reparación a su costa de los daños y perjuicios a los particulares afectados.

b) Derechos, bienes, valores y principios afectados. Las Administraciones públicas ejercen sus competencias en materia de ruidos bien legislando, dictando normas, bien ejecutando, dictando actos administrativos en ejercicio de las competencias que les confieren dichas normas jurídicas. En un caso y en otro deben tener en cuenta un conjunto de derechos, bienes, valores y principios mucho más amplio y de distinta naturaleza de lo que en otros tiempos, en este ámbito, pudiera ser exigible. Así: el descanso nocturno, la libre circulación de personas y bienes, el derecho a «la propia vida en un sentido amplio no sólo físico», el derecho de acceso a las propias viviendas a veces dificultado por las concentraciones humanas, STSJ de Andalucía, Sala de lo CA (Sevilla), de 29 de octubre de 2001; el descanso y ritmo de vida normal trastornado por las molestias que ocasionan determinadas situaciones ruidosas, STSJ de Andalucía, Sala de lo CA (Sevilla) de 29 de marzo de 2001; la tranquilidad del vecindario, STSJ de Murcia, Sala de lo CA, de 29 de octubre de 2001; la calidad de vida y la salud física de las personas, STSJ Valencia, Sala de lo CA, de 9 de julio de 2001; la salud, la tranquilidad y la protección del medio ambiente, STSJ de Cataluña, Sala de lo CA, de 11 de mayo de 2000; el derecho a un medio ambiente adecuado, la salud, la integridad física, el derecho a la inviolabilidad del domicilio, STSJ de Valencia, Sala de lo CA, de 1 de junio de 1999; el derecho a la inviolabilidad del domicilio y a la integridad física y moral, STSJ de Baleares, Sala de lo CA, de 29 de julio de 1999; la degradación del ambiente, salud física y psíquica y la inviolabilidad del domicilio, así como el derecho a disfrutar de este último de forma tranquila, STSJ de Valencia, Sala de lo CA, de 29 de junio de 1998; el derecho colectivo al descanso nocturno, STSJ de Canarias, Sala de lo CA (Santa Cruz de Tenerife), de 29 de julio de 1998; valores ciudadanos innegables y de un bien central en lo que a la calidad de vida se refiere, STSJ de Baleares, Sala de lo CA, de 16 de junio de 1998 68; seguridad ciudadana, la protección del medio ambiente, la tranquilidad de las

\footnotetext{
${ }^{66}$ STSJ de Murcia, Sala de lo CA, de 29 de octubre de 2001.

${ }^{67}$ Entre otras, STSJ de Andalucía, Sala de CA (Sevilla), de 29 de marzo de 2001, STSJ de Murcia, Sala de lo CA, de 29 de octubre de 2001, y SSTSJ de Valencia, Sala de lo CA, de 7 de marzo de 1997 y 9 de julio de 2001.

${ }^{68}$ En idéntico sentido STSJ de Baleares, Sala de lo CA, de 24 de septiembre de 1996.
} 
personas y la salud individual de las personas, STSJ de Madrid, Sala de lo CA, de 18 de junio de 1998; la salud de las personas, la inviolabilidad del domicilio y el disfrute de éste, y la intimidad personal y familiar, STSJ de Valencia, Sala de lo CA, de 7 de marzo de 1997.

c) La influencia de la doctrina del TEDH. Ha sido en el ámbito de la jurisprudencia menor donde, primeramente, ha encontrado acogida la doctrina establecida por el TEDH, sobre todo la sentada en las SS. de 21 de febrero de 1990 y 9 de diciembre de $1994{ }^{69}$, donde se consideró que la emisión de ruidos y sustancias vulnera el derecho a la inviolabilidad del domicilio y a la intimidad personal y familiar contemplados en el artículo 8 del CEDH ${ }^{70}$. Resultando importante resaltar que en algunas de estas resoluciones, como en la STSJ de Valencia, Sala de lo CA, de 1 de junio de 1999, se ha apreciado gran similitud entre los artículos 8 del CEDH y 18.1 y 2 de la CE ${ }^{71}$.

d) Efectos del ruido. En el apartado b) ya hemos dejado constancia de los bienes y derechos que pueden resultar afectados como consecuencia de emisiones procedentes del ruido. La tranquilidad, el descanso, la salud, el domicilio, la intimidad, el medio ambiente son susceptibles de ser afectados negativamente por el ruido. No obstante la pluralidad de bienes y derechos que pueden resultar influenciados por este agente contaminante, sobre todo, en este punto, queremos resaltar el carácter nocivo de aquél y la «gravedad» que pueden revestir sus efectos para la salud humana. De esta circunstancia se han hecho eco especialmente las SSTSJ de Valencia, Sala de lo CA, de 29 de junio de 1998 y 1 de junio de $19999^{72}$.

69 Véase el apartado A) del punto 4 de estas Consideraciones Finales.

70 SSTSJ de Valencia, Sala de lo CA, de 7 de marzo de 1997, 29 de junio de 1998 y 1 de junio de 1999, STSJ de Baleares, Sala de lo CA, de 29 de julio de 1999. También, en el ámbito civil, ha encontrado acogida la jurisprudencia del TEDH, entre otras, en SAP de Murcia de 24 de mayo de 1997, SAP de Toledo de 11 de marzo de 1999, y en SAP de Madrid de 20 de noviembre de 2000.

71 Efectivamente, se dice literalmente en esta S.: «pues bien, desde esta filosofía, y atendida la gran similitud de contenido entre el repetido artículo 8 del CEDH y el artículo 18.1 y 2 de la Constitución Española, hay que construir, desarrollar y trabar el núcleo intimidad-protección del domicilio frente a determinadas intromisiones sonoras, para, finalmente, concluir que la degradación del medio ambiente a través del excesivo ruido supone la violación de los derechos fundamentales protegidos en dicho artículo 18». Cfr. FJ 6 de la STC 119/2001, de 24 de mayo, donde el TC no parece apreciar tanta «similitud» entre uno y otro precepto.

72 En la primera de las Sentencias citadas se dice: «éste ha debido causar, inexorablemente, unas importantes molestias y perjuicios físicos y psíquicos por impedir o dificultar notablemente a éstos la conciliación del sueño nocturno que constituye, desde luego, una de las facetas físicas ineludibles - su desarrollo continuado y durante un número de horas suficientes - para los seres humanos, existiendo también notables afectaciones, según los estudios científicos practicados al efecto, desde 
e) La defensa frente al ruido por la vía de la protección jurisdiccional de los derechos fundamentales. La doctrina científica ${ }^{73}$ primero y la jurisprudencia del TEDH después, pusieron de manifiesto que la emisión de determinados ruidos constituía una vulneración del derecho a la inviolabilidad del domicilio y a la intimidad personal y familiar. Derechos fundamentales consagrados en los artículos 18.1 y 2 de la CE y 8 del CEDH. Esta posición fue acogida por la jurisprudencia de nuestros Tribunales Superiores de Justicia que amplió, aun más, el catálogo de derechos fundamentales que podían resultar quebrantados por conductas productoras de ruidos, considerando, en este sentido, el derecho a la vida y la integridad física y moral estipulado en el artículo 15 de la CE. Así, en SSTSJ de Valencia, Sala de lo CA, de 7 de marzo de 1997, 29 de junio de 1998, 1 de junio de 1999, y 9 de julio de 2001, los recursos que se resuelven se interponen y sustancian por la vía de la Ley 62/1978, de 26 de diciembre, de Protección Jurisdiccional de los Derechos Fundamentales de la Persona. En otros casos, como en STSJ de Baleares, Sala de lo CA, de 29 de julio de 1999, el recurso no se tramita por la indicada vía pero el Tribunal deja constancia de que determinados niveles de ruidos pueden constituir una vulneración de los citados preceptos constitucionales. Y, por último, en otros casos, sin minusvalorar la gravedad de los efectos que puede producir el ruido, el Órgano jurisdiccional considera que dichas molestias son más bien incardinables en el artículo 45 de la CE y, consecuentemente, frente a las mismas no se puede utilizar el procedimiento preferente y sumario previsto en la citada Ley 62/1978, de 26 de diciembre ${ }^{74}$.

\begin{abstract}
el nivel auditivo, somático (dolores de cabeza, vómitos, diarreas,...) y psicosomático (estrés, depresión)». Igualmente, en el voto particular formulado a la S. citada en segundo lugar, se dice que: «dichos estudios revelan que el ruido constante daña seriamente la salud física y psíquica de las personas no poniéndose de acuerdo los expertos sobre la incidencia del ruido en las diferentes personas o grupos de personas, de todas formas, según se desprende de ambos informes se podrían distinguir tres grupos de afectaciones: 1. A nivel auditivo. 2. A nivel somático, dolores de cabeza, vómitos diarrea, etc. 3. A nivel psicosomático, estrés, depresión e incluso posibles tendencias al suicidio». Vid. notas 82 y 84 .
\end{abstract}

73 Véase el punto 3 de estas Consideraciones Finales.

${ }^{74}$ Es el caso de la STSJ de Galicia, Sala de lo CA, de 22 de octubre de 1998, que desestima el recurso CA interpuesto, por la vía de protección jurisdiccional de los derechos fundamentales, contra la desestimación presunta por silencio administrativo de la solicitud formulada por los recurrentes al Ayuntamiento para que iniciara expediente sancionador y resolviera paralizar el funcionamiento de una discoteca, todo ello con fundamento en el nivel de ruidos que producía dicho establecimiento y que los actores estaban soportando en su domicilio, alegándose en este sentido que se estaban vulnerando los artículos 15 y 18 de la CE. Afirma el Tribunal que: «sin desconocer ni minusvalorar la gravedad de las molestias que a los habitantes de una vivienda pueda producir la emisión nocturna y aun diurna de ruidos excesivos que provengan del exterior, sobre cuyo extremo no es necesario extenderse más en este momento, es lo cierto que la protección contra ello no alcanza entidad constitucional; por muy generosamente que quiera interpretarse el artículo 15 de la Constitución, aquí no está en juego la vida de las personas ni son aquéllos constitutivos de torturas, en la acepción que la 
f) El componente ambiental en la vulneración de derechos fundamentales. Tal y como venimos exponiendo en estas Consideraciones Finales no cuesta trabajo entender que el ruido, como forma de energía y emitido a unos determinados niveles, de forma individual ${ }^{75}$, atenta contra el medio ambiente, produce efectos negativos sobre la salud de las personas y vulnera derechos fundamentales, sobre todo, los consagrados en los artículos 15 y 18.1 y 2 de la CE. Ahora bien, dicho lo anterior, conviene resaltar en este punto la posición mantenida en algunas resoluciones de las aquí estudiadas en las que, a nuestro entender, sobre todo en el caso del derecho a la inviolabilidad del domicilio y a la intimidad personal y familiar, su vulneración se condiciona a «una degradación del medio ambiente». Es decir, la degradación del medio ambiente que produce el ruido es lo que provoca la vulneración del derecho a la inviolabilidad del domicilio y a la intimidad personal y familiar ${ }^{76}$.

g) Esfuerzo de coordinación entre las Administraciones públicas implicadas. Una de las características del ruido es la pluralidad de fuentes que lo producen y la diversidad de efectos y consecuencias que provoca. Dichas fuentes, efectos y consecuencias van a afectar a los más variados ámbitos competenciales. Por ello, la «problemática del ruido» es una cuestión donde, en el ámbito de sus respectivas competencias, habrán de emplearse ${ }^{77}$ las distintas Administraciones territoriales, lo que, a su vez,

cultura jurídica ha dado a esta palabra, ni de tratos inhumanos o degradantes (...). Y por lo que afecta al artículo 18, ciertamente que proclama la inviolabilidad del domicilio, en expresión que no puede extraerse de su contexto ni interpretarse asistemáticamente aislándolo de su ubicación en el texto ni de su relación con el resto del artículo, y así tenemos que a modo de interpretación auténtica, (...); en definitiva, una interpretación finalista del precepto nos conduce a verlo como una protección del derecho al secreto y a la intimidad personal y familiar concretada en la seguridad que proporciona el valladar del propio domicilio. (...). Y desde luego que no es esto lo que está en cuestión en el caso que nos ocupa, mucho más fácilmente incardinable en el artículo 45 del Texto Constitucional - derecho al medio ambiente - y en el 47 — derecho a la vivienda digna y adecuada — o dicho con otras palabras, derecho a la calidad de vida; pero éstos, que deben inspirar la práctica judicial (art. 53), no tienen acogida posible en el proceso preferente y sumario aquí seguido; son temas de legalidad ordinaria que esta sentencia deja imprejuzgados».

75 Vid. STSJ de Madrid, Sala de lo CA, de 18 de junio de 1998, y STSJ de Cataluña, Sala de lo CA, de 11 de mayo de 2000.

76 STSJ de Valencia, Sala de lo CA, de 29 de junio de 1998, donde se afirma que: «pues bien, desde esta filosofía, y atendida la gran similitud de contenido entre el repetido artículo 8 del CEDH y el artículo 18.1 y 2 de la Constitución Española, hay que construir, desarrollar y trabar el núcleo intimidad-protección del domicilio frente a determinadas intromisiones sonoras, para, finalmente, concluir que la degradación del medio ambiente a través del excesivo ruido supone la violación de los derechos fundamentales protegidos en dicho artículo 18. Postura que, en definitiva, encuentra también su apoyo en la doctrina del Tribunal Constitucional, el cual, en la Sentencia 22/1984, de 17 de febrero...». En idéntico sentido STSJ de Valencia, Sala de lo CA, de 1 de junio de 1999.

${ }^{77}$ Esta circunstancia, ante un supuesto de ruidos generados por la denominada «movida», ha sido 
va a exigir un esfuerzo de cooperación, coordinación y colaboración entre todas ellas.

h) La «movida». Es una fuente productora de ruidos donde, directa o indirectamente, distintos sectores del interés público protegido por la ley pueden resultar afectados. En STSJ de Andalucía, Sala de lo CA (Sevi1la), de 29 de octubre de 2001, se dice que «la «movida» es un fenómeno sociológico producto de causas heterogéneas que está provocando verdaderos estragos en la Sociedad por el abuso del consumo de alcohol y drogas, violencia en las personas y bienes y molestias a los vecinos de aquellas zonas donde por una u otra causa son elegidas por los jóvenes para concentrarse». El Tribunal, aun cuando reconoce la responsabilidad en este problema de otros institutos sociales ${ }^{78}$, obliga a las Administraciones, cada una en el ámbito de sus respectivas competencias, a que, en el marco de la legalidad, adopten las medidas necesarias para paliar los efectos que dicho fenómeno produce. Y ello, aun cuando dichas medidas resulten impopulares y, consecuentemente, puedan producir algún coste electoral en el sector de la población afectada, pues, en este sentido, se

puesta de manifiesto en la STSJ de Andalucía, Sala de lo CA (Sevilla), de 29 de octubre de 2001, donde se dice que: «compartimos igualmente que no sólo la Administración Municipal, sino la del Estado y Comunidad Autónoma en el ámbito de sus respectivas competencias puede combatir, mediante el ejercicio de la acción policial correspondiente, el tráfico de estupefacientes, la violencia callejera, etc., para que se haga efectiva la Seguridad Ciudadana». Sin embargo, en S. de este mismo Tribunal, Sala de lo CA (Sevilla), de 2 de marzo de 1999, que resuelve un recurso CA interpuesto contra la Consejería de Medio Ambiente de la Junta de Andalucía por omisión de información e inactividad frente al funcionamiento ilegal de varias discotecas que impedían el descanso de las personas que vivían en zonas próximas a la misma, el Tribunal afirma que: «los hechos anteriores, sustento de la demanda, revisten indudablemente una gravedad cierta. La prueba aportada demuestra que los ruidos producidos durante la noche en los días de verano han sido verdaderamente insoportables y por ello generadores de molestias que han llegado al punto de trastornar el descanso normal, y el ritmo de vida de las personas afectadas por la situación». No obstante la entidad y naturaleza de los hechos, el Órgano jurisdiccional no accede a la pretensión de los demandantes consistente en la declaración de funcionamiento anormal de la citada Consejería de Medio Ambiente demandada. Pues, se entiende, que los establecimientos que generaban las molestias estaban sujetos a licencia municipal siendo la Administración local la competente para su otorgamiento o denegación y, por tanto, la competente, también, para actuar en estos casos. De este modo, se afirma, la Administración autonómica ambiental no podía hacer más de lo que hizo, es decir, recabar información sobre dichos establecimientos y advertir al Ayuntamiento competente que exigiera los permisos correspondientes. Todo ello, se razona, con fundamento en el artículo 42.3.b) de la Ley General de Sanidad de 1986 que atribuye la policía de ruidos a los ayuntamientos, por lo que la Consejería de Medio Ambiente no podía cerrar, como pretendía el actor, dichos establecimientos. En este caso, el Tribunal no parece tener en cuenta las competencias de la Administración autonómica andaluza en materia de actividades molestas, insalubres, nocivas y peligrosas.

${ }^{78}$ En este sentido en la indicada S. se dice: «también es cierto que no puede el Ayuntamiento usar métodos represivos salvajes ni impedir concentraciones de jóvenes o el consumo de alcohol o la utilización de vehículos de motor y que la responsabilidad de los padres, educadores y de la sociedad en general no es ajena al fenómeno, porque la falta de educación, cultura, solidaridad y civismo de nuestros jóvenes son la causa de los efectos indeseables de este fenómeno social». 
afirma en la citada S. que «no hay que olvidar que la Administración como proclama el artículo 103 de la Constitución debe servir con objetividad los intereses generales con sometimiento pleno a la ley y al Derecho así como a los fines que la justifican (art. 106 de la Constitución») ${ }^{79}$.

i) Intereses enfrentados. Como resulta obvio en el caso del ruido y, sobre todo, cuando su fuente productora son establecimientos públicos puede darse una confrontación entre bienes y derechos constitucionalmente protegidos. El derecho al descanso, a la salud, a la inviolabilidad del domicilio, a la intimidad y al disfrute de un medio ambiente adecuado pueden entrar en conflicto con el derecho a divertirse y al libre desarrallo de actividades empresariales. En nuestra opinión, en estos casos, siempre deberían prevalecer los primeros sobre los segundos. En este sentido parece pronunciarse la STSJ de Baleares, Sala de lo CA, de 29 de julio de $1999^{80}$, mientras que en STSJ de Valencia, Sala de lo CA, de 1 de junio de 1999, parece optarse por una compaginación y compatibilización entre los intereses en juego.

j) La incidencia de la jurisprudencia menor en la protección penal frente al ruido. No son infrecuentes los supuestos ${ }^{81}$ que han dado origen a causas criminales seguidas ante este Orden jurisdiccional que han tenido su origen en conductas ruidosas. Ya pusimos de manifiesto, en otro lugar de este trabajo, las dificultades que presenta una acción de esta naturaleza para que, finalmente, termine siendo constitutiva del tipo del artículo 325 del CP95, y la ausencia de previsión expresa en el ámbito de las faltas para conductas de esta clase. En el ámbito de esta jurisprudencia hemos hallado algunas resoluciones que han venido a suavizar las dificultades antes apuntadas en relación con el citado CP95. De este modo, la SAP de Cantabria de 6 de septiembre de 1999, considera la acción de provocar ruidos durante la noche con la consecuente molestia para los vecinos como típica del artículo $620.2 .^{\circ}$ del $\mathrm{CP}{ }^{82}$. Especial mención requiere

\footnotetext{
${ }^{79}$ En este sentido cfr. el voto particular formulado a la STSJ de Valencia, Sala de lo CA, de 29 de junio de 1998.

${ }^{80}$ En sentido similar STSJ de Murcia, Sala de lo CA, de 29 de octubre de 2001.

81 Así, a modo de ejemplo, véanse, SAP de Valladolid de 29 de marzo de 2000, SAP de Las Palmas de 16 de octubre de 1999, SAP de Sevilla de 19 de marzo de 1999, SAP de Cádiz de 2 abril de 1997, SAP Alicante de 6 de febrero de 1997, y SAP de Tarragona de 9 de abril de 1996.

${ }^{82}$ Se dice en esta S.: «(...). Y en cuanto a la tipicidad o atipicidad de la acción consistente en producir ruido durante la noche, con la única finalidad de molestar a determinados vecinos dificultándoles el descanso y el sueño, clara resulta su incardinación en la previsión del artículo $620.2{ }^{\circ} \mathrm{CP}$, partiendo como partimos de que el descanso y el sueño son verdaderos e importantes derechos que asisten a cualquier ciudadano, necesarios para mantener el equilibrio psicosomático y reponer las fuerzas perdidas, que no pueden ser impedidos por nadie sin causa justificada».
} 
la SAP de Palencia de 9 de noviembre de 2000 que, en relación con unos hechos consistentes en la emisión de ruidos por encima de lo legislado por un establecimiento público ${ }^{83}$ que ocasionaba molestias ${ }^{84}$ a los vecinos de las fincas de la Comunidad donde dicho establecimiento estaba ubicado, considera los hechos probados constitutivos de un delito contra el medio ambiente regulado en el artículo 325, en relación con los artículos 327 y 129.1 del CP. Tres cuestiones interesa destacar de esta S., primero, a la vista del tenor literal del artículo 325 del CP95 para que tengan lugar los elementos del tipo no tiene que producirse acumulativamente la situación de riesgo o peligro para el equilibrio de los recursos naturales y la salud de las personas, sino que basta con que dicha situación se dé en cualquiera de los dos bienes jurídicamente protegidos ${ }^{85}$; segundo, por «grave», debe entenderse aquello que es importante, y por enfermedad importante debe entenderse sin ninguna duda el desarrollo de brotes psicóticos, la provocación de estrés en el parto y la posibilidad de estrés en el feto, y la posibilidad de agravamiento de enfermedades preexistentes como la esclerosis, y tercero, los daños morales deben entenderse por las molestias y padecimientos físicos ocasionados.

\footnotetext{
${ }^{83}$ Concretamente, una Sala de fiestas.
}

${ }^{84}$ Se dice en el apartado 12 de los hechos probados: «... la exposición de una persona a los niveles de ruidos de entre 30 y $40 \mathrm{~dB}(\mathrm{~A})$, reiterada, pero no permanente, de forma que se corresponde con las noches de los fines de semana, durante un período de tiempo que no tiene necesariamente que ser superior a 9 meses, y así también la exposición a tal nivel de ruido durante 4 noches seguidas, puede causar afectaciones, dependiendo de la sensibilidad que cada persona pueda tener, de tipo psíquico y psicológico, con desarrollo de trastorno de sueño en forma de insomnio, que se originan cuando los niveles sonoros impiden conciliar el sueño o provocan despertares tempranos, alteraciones que alteran el ritmo de vida normal pudiendo provocar estados de fatiga, cansancio, irritabilidad, disminución de atención y concentración y consecuentemente de los rendimientos laborales o escolares; pudiéndose llegar al desarrollo de brotes psicóticos (con cuadros alucinatorios, delirantes y de alteraciones de conciencia), o a la existencia de síntomas vegetativos, tales como taquicardia, hipertermia, aumento de la sensación de hambre, hiperfagia, cefaleas, gastralgias... Las consecuencias de la afectación aludida en niños puede producir trastornos de conducta; en mujeres embarazadas puede interferir en el embarazo y originar un parto prematuro además de someter a estrés al feto que le supone una situación de especial riesgo durante el período neonatal, y así también tal afectación puede producir el agravamiento de enfermedades preexistentes como la esclerosis».

\footnotetext{
${ }^{85}$ A este respecto se dice en la S.: «el artículo 325 del Código Penal castiga la realización de unos concretos actos que describe que "puedan perjudicar gravemente el equilibrio de los sistemas naturales"; y a continuación de un punto y seguido determina cual será la pena a imponer, "si el riesgo de grave perjuicio fuese para la salud de las personas" sin emplear expresión alguna que indique la necesidad de acumulación de los dos peligros para que pueda ser castigada la existencia de peligro para la salud de las personas, lo que indica la separación de los dos tipos básicos, por más que alguno de los requisitos del tipo sean comunes a ellos. A mayor abundamiento no se entendería que la realización de los actos que se describen en el artículo 325 del Código Penal, sean punibles si pueden perjudicar únicamente el equilibrio de los sistemas naturales, y no en el caso de que el potencial perjuicio sea para las personas, y ello en razón a la importancia de los bienes jurídicos protegidos que se describen el en artículo 325 del Código Penal».
} 
5. En nuestra opinión, no se puede cuestionar que la STC 119/2001, de 24 de mayo, constituye un avance importante en la protección frente al ruido, y ello, tanto ante la Administración pública como ante los Tribunales de Justicia. Pues el TC, de una parte, recrimina la inactividad administrativa considerándola generadora de responsabilidad patrimonial ${ }^{86} \mathrm{y}$, de otra parte, acogiendo la doctrina de TEDH, establece que la contaminación acústica constituye un agente con capacidad de vulnerar los derechos fundamentales consagrados en los artículos 15 y 18.1 y 2 de la CE. $\mathrm{Y}$ en relación con este último extremo, se afirma que: primero, hay vulneración del precepto citado en primer lugar «cuando los niveles de saturación acústica que deba soportar una persona, a consecuencia de una acción u omisión de los poderes públicos, se ponga en peligro grave e inmediato la salud», y, segundo, hay vulneración del derecho a la intimidad personal y familiar cuando los ruidos se soporten en el ámbito domiciliario e impidan o dificulten «gravemente» el libre desarrollo de la personalidad, y sean calificables como evitables, insoportables y prolongados.

Ahora bien, no obstante lo anterior, tanto en un caso como en otro la vulneración de los citados derechos fundamentales se condiciona rigurosamente. En el supuesto del derecho a la integridad física y moral, a que el peligro para la salud de las personas sea «grave» e «inmediato»; $y$, en el caso del derecho a la intimidad personal y familiar, a que los ruidos sean evitables, insoportables y prolongados, se perciban en el domicilio e impidan o dificulten "gravemente» el desarrollo de la personalidad. De este modo, la necesaria concurrencia de los requisitos y circunstancias indicadas para que exista vulneración de los citados derechos fundamentales restringe su ámbito de protección, dificultando notablemente las posibilidades reales de que los Tribunales de Justicia puedan apreciar dicha vulneración ${ }^{87}$. Por ello debemos entender que la doctrina sentada en esta Sentencia es más restrictiva que la establecida por los Tribunales Superiores de Justicia y las Audiencias Provinciales a que nos hemos referido en el punto anterior. Debiendo entender, también, que dicha restriccción, en cierta medida, relativiza valores y principios constitucionales tan importantes como la calidad de vida, la dignidad de la persona y el libre desarrollo de la personalidad. En cualquier caso, la doctrina sentada en esta Sentencia, así como la establecida so-

\footnotetext{
${ }^{86}$ No debemos olvidar que tanto en la STSJCV recurrida en amparo como en la STC 119/2001, de 24 de mayo, no se accede a lo pretendido por falta de pruebas.

${ }^{87}$ Así lo ha puesto de manifesto M. Pulido QueCEDo (en «Sobre la defensa...», cit., p. 12), cuando dice que «pocas veces, con la doctrina que esta sentencia establece, podrá obtenerse una sentencia estimatoria por lesión del derecho a la intimidad familiar, y más complicada aún la estimación de una lesión del derecho a la integridad...».
} 
bre este tema por otros Órganos jurisdiccionales en parte aquí citada, y teniendo en cuenta los distintos ámbitos de la realidad social a que afecta la «problemática del ruido», deberían servir de base y acicate para que el legislador afronte la regulación básica de esta materia, estableciendo así una ordenación común en cuyo marco las CC.AA. y las Corporaciones Locales ejercieran sus competencias. 


\section{Crónicas y Documentos}

REAL-2002, núm. 288. PEREZ MARTOS, JOSE. LA PROTECCION JURISDICCIONAL FRENTE AL ... 
